\title{
Tracheobronchomalacia
}

\section{A Rare Cause of Respiratory Distress in Children}

\author{
Lt Col B Moorthy \\ MD, MRCP, RAMC \\ Consultant Paediatrician
}

\section{Capt H Robertson} MRCP, RAMC

Specialist in Paediatrics

BMH Rinteln, BFPO 29

SUMMARY: Tracheobronchomalacia is a rare cause of respiratory distress in children. An infant with tracheobro声 chomalacia is presented. The aetiology, pathophysiology and management are discussed.

\section{Case Report}

A six month old male infant was admitted to the Children's Ward at the Cambridge Military Hospital with symptoms of increasing wheeze. He had been symptomatic for nearly two months prior to admission with cough and wheeze for which he had been prescribed antibiotics by the General Practitioner. There was no

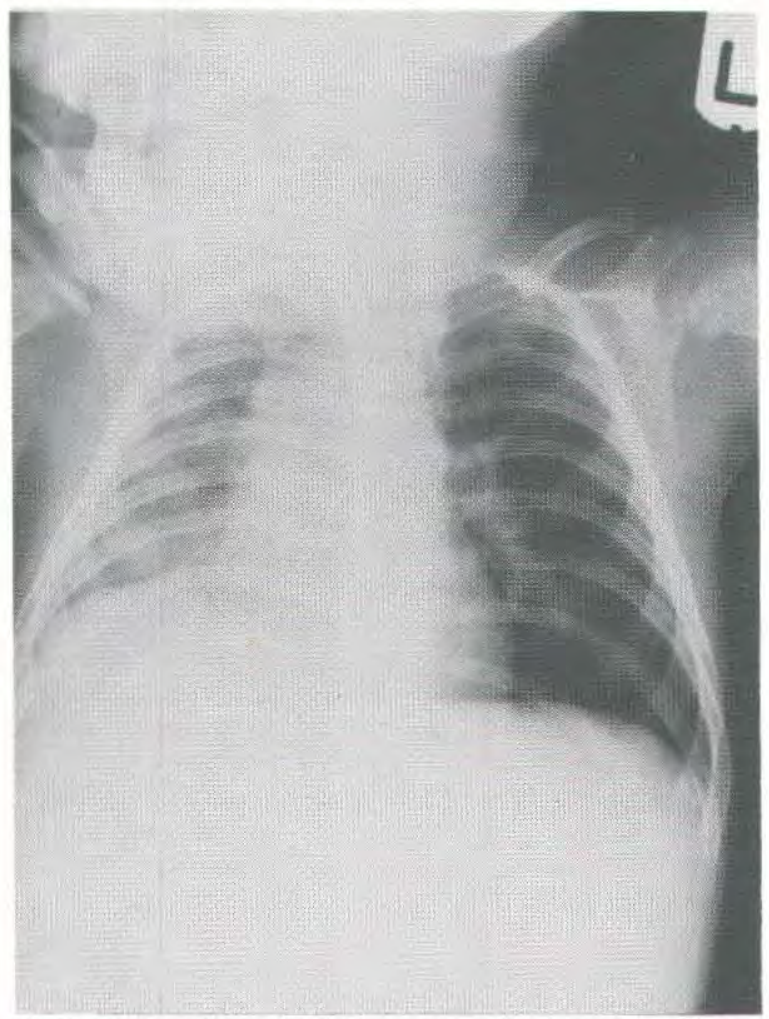

Fig 1. X-ray of the chest (expiratory film) shows evidence of underinflation of the right lung with hyperinflation of the left lung with mediastinal shift.

history suggestive of a foreign body or choking and $\vec{\omega}$ did not have any other systemic symptoms.

Birth history, past history and family history we non-contributory. On examination, at the time of mission, he was well grown, apyrexial, acyanotic but qn $_{1}$ respiratory distress. There was no evidence suggestion af

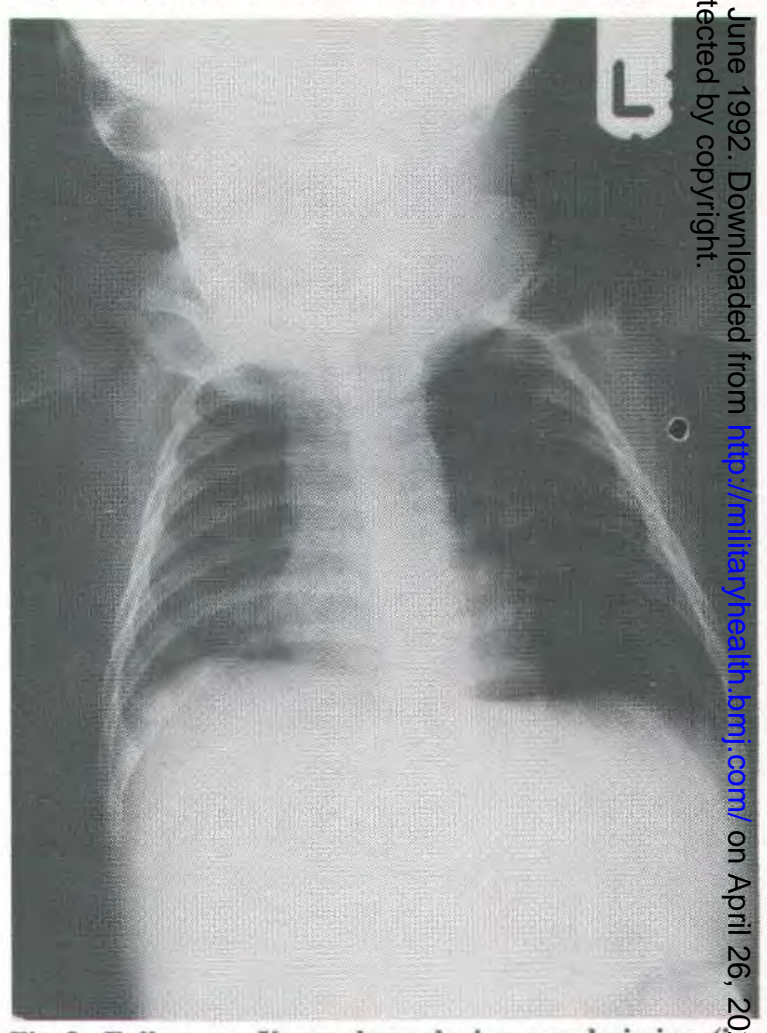

Fig 2. Follow up $\mathbf{X}$-ray done during re-admission (in spiratory film) shows hyperinflation of the left lung wift mediastinal shift. 

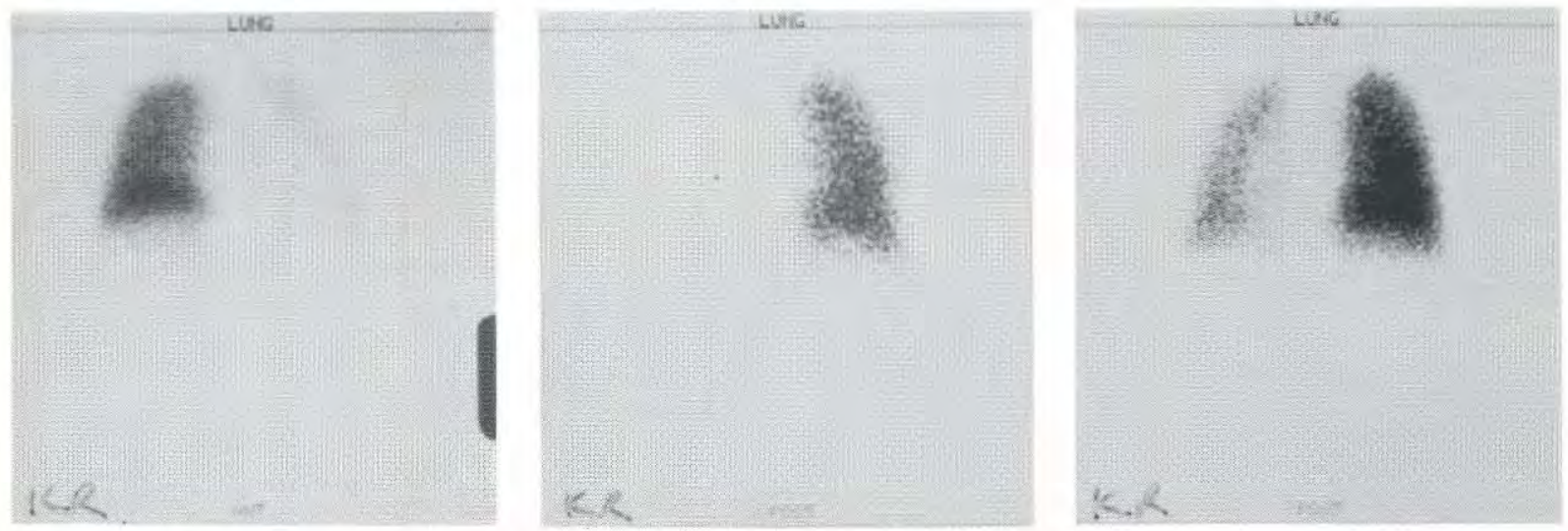

a.
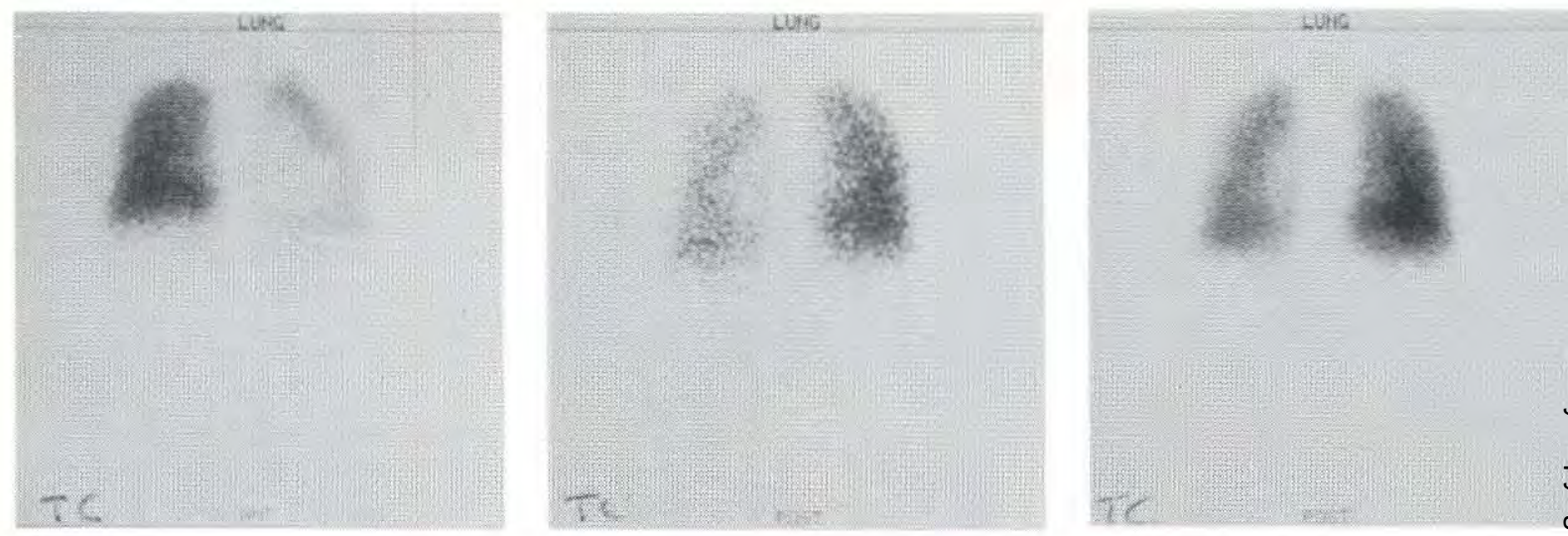

b.

Fig 3. Krypton/Technetium 99 ventilation/perfusion scan.

a. Impaired ventilation of the left lung (41\%). Right lung $(59 \%)$ shows patchy abnormalities of the upper lobe and apical segment of the lower lobe.

\section{b. Decreased perfusion of the left lung $(41 \%)$ and right lung $(59 \%)$.}

\section{(A. Krypton: 1 anterior $2 \& 3$ posterior. B'. Technetium: 1 anterior 2 \& 3 posterior).}

chronic respiratory disease such as finger clubbing, Harrison's sulcus or pigeon chest. Systemic examination was unremarkable, except for diffuse rhonchi and crepitations.

Full blood count and biochemical screen were normal. Initial chest X-ray showed an under-inflated right lung with hyperinflation of the left lung (Fig 1), which was thought to be due to mucous plugging. He was started on oral erythromycin, nebulised salbutamol and regular chest physiotherapy. He improved over the next 72 hours and follow-up X-ray of the chest was normal. He was discharged home on oral salbutamol and erythromycin with advice to continue regular chest physiotherapy. He was re-admitted 17 days later, with symptoms of increasing respiratory distress and wheeze. Repeat chest X- ray revealed hyperinflation of the left lung with mediastinal shift to the right (Fig 2). A diagnosis of foreign body in the left main bronchus was considered, and he was transferred to the Hospital for Sick Children, Great Ormond Street, London, for bronchoscopy and further respiratory investigations. On examination of $\delta$ the respiratory system at the Hospital for Sick Children, he had tachypnoea (respiratory rate 50/minute) in- 을 tercostal recession, bilateral wheeze and decreased air $D$ entry in the base of the left lung. Bronchoscopy showed minimal subglottic narrowing, a tracheomalacic segment between middle and distal thirds with about $20 \%$ nar- o rowing, and a $2 \mathrm{~cm}$ long bronchomalacic segment of the $N$ left main bronchus leading on to $80-90 \%$ obstruction. Barium swallow and $2 \mathrm{D}$ echocardiogram were normal, $\underset{2}{2}$ 
ruling out vascular ring, double aortic arch or pulmonary artery sling. Magnetic Resonance Imaging (MRI) of the chest did not reveal any abnormality to cause the tracheobronchomalacia. A ventilation perfusion scan showed decreased ventilation and perfusion on both sides, the left side showing $33 \%$ of overall ventilation and $41 \%$ of overall perfusion (Fig 3 ).

The child is now nearly three years old and has remained symptomatically well, without further respiratory distress, requiring hospital admission, the use of regular bronchodilators or antibiotics. Chest X-ray has remained normal. $\mathrm{He}$ is growing and developing normally. It is probable that with advancing age, the tracheobronchomalacic segments have become more competent, preventing further respiratory complications.

\section{Discussion}

Respiratory distress is a common reason for hospital admission in childhood. Chest infection, either bacterial or viral, and bronchial asthma are the two most common causes. Foreign body inhalation and congenital abnormalities of the respiratory tract, such as tracheobronchomalacia, are rarer causes and require flexible bronchoscopy to confirm the diagnosis and for removal of the foreign body.

Tracheobronchomalacia can be either congenital or acquired (1). Congenital tracheobronchomalacia may be an isolated abnormality, or be associated with other congenital abnormalities such as laryngomalacia, choanal atresia or cleft palate (2). Recently Larsen's syndrome has been associated with tracheobronchomalacia (3). Congenital heart disease with enlarged pulmonary arteries can present as bronchomalacia due to external compression (4).

Acquired tracheobronchomalacia, an adult disease, usually follows chronic bronchitis, bronchial carcinoma or pulmonary tuberculosis and often progresses with increasing respiratory morbidity and mortality (1). Chronic inflammatory diseases affecting the respiratory tract break the protein-polysaccharide bond, which leads to the loss of resilience of hyaline cartilage, causing tracheobronchomalacia (5). The area of tracheobronchomalacia can be either isolated or multiple (6) and rarely bronchomalacia can be familial (7). More recently, with increasing survival of extremely low birth weight babies and the complication of bronchopulmonary dysplasia, bronchomalacic segments have been observed on flexible bronchoscopic examination for worsening respiratory functions (8). Whether these areas of bronchomalacia are congenital or acquired due to bronchopulmonary dysplasia is debatable. Children with non-productive intractable cough, usually considered to be psychogenic, should have flexible bronchoscopic examination under local anaesthesia and sedation to rule out an underlying abnormality of the tracheobronchial walls, as an increased incidence of tracheobronchomalacia in these patients has recenty been reported (9). Tracheobronchomalacia produce a flaccid airway, which has an adequate lumen on ins雨iration but develops obstruction on expiration. This @en lead to collapse of the airway, stridor and respiratgy failure, infrequently needing ventilatory suppert $(10,11,12,13)$.

As compared to adults the tracheobronchial tre $\Rightarrow$ in infants is extremely soft and the mucosa is redundant especially around the carina (14). During forced expleation, crying and coughing, the lumen may become campletely obliterated due to increased intrathoracic pre sure exceeding the transbronchial pressure, leading to herniation of the posterior membrane and anterio-posterior narrowing (15).

Usually children with primary tracheobrohchomalacia recover spontaneously and becogfie asymptomatic by the second year of life $(2,7)$. Childmen with congenital heart disease, enlarged pulmonary $\mathrm{Gr}$ teries and secondary bronchomalacia will improve with surgical correction of the heart defect and arteriopexy $(4,16)$. Recently in children with bronchomalacia ond respiratory failure, endoscopic placement of expandable stents has been found to be useful, thus avoiding cœinplex high risk surgical procedures such as arteriogegy, tracheopexy, external stenting, tracheobronchi construction and pneumonectomy $(17,18)$.

\section{Acknowledgement}

We would like to thank Major D Whitehouse, MR RAMC for his suggestions and Mrs P Tracey for figndly preparing the manuscript.

\section{REFERENCES}

1. NuUtinen J. Acquired tracheobronchomalaciaڤbronchological follow-up study. Ann Clin $\mathrm{B} e s$ 1977; 9: 359-364.

2. Baxter J D, Dunbar J S. Tracheomalacia. Otol Rhinol Laryngol 1964; 72: 1013.

3. Rock M J, Green C G, Pauli R M, Peters Meg Tracheomalacia and Bronchomalacia associated with Larsen's Syndrome. Paed Pulmonology 1988; 5: $55-59$

4. Stillin G, Jonas R A, Goh T H, Brawn WNT, Venables A W, MeE R B. Surgical treatmentof absent pulmonary valve syndrome in infants $\rightarrow$ Irelief of bronchial obstruction. Ann Thoracic Sitrg $1983 ; 36: 468-475$.

5. MaCMohan H E, Ruggieri J. Congen Segmental bronchomalacia. Am J Dis Child 16்9; 118: 923.

6. Kissane J M, SMith M G. Pathology of infancy and childhood. CVMosby \& Co, 1967.

7. Agosti E, De Fillippi G, Fior R, Chiussid Generalised bronchomalacia - case report. Acta Paediatr Scand 1974; 63: 616.

8. Miller R W, Woo P, Kellman R K, Slagle PS. Tracheobronchial abnormalities in infants bronchopulmonary dysplasia. J Pediatr 1987; 111:(5) $779-782$. 
9. WoOD R E. Localised tracheomalacia or bronchomalacia in children with intractable cough. $J$ Pediatr 1990; 116:(3) 404-406.

10. Gupta T G, Goldberg S J, Lewis E. Congenital bronchomalacia. Am J Dis Child 1968; 118: 88.

11. LyNCH J I. Bronchomalacia in children. Clin Pediatr 1970; 9: 279.

12. Neijens H J, Kerrebijn K F, Smelhout B. Successful treatment with CPAP of two infants with bronchomalacia. Acta Paediatr Scand 1978; 67: 293.

13. Miller R W, Pollack M M, Murphy T M, Fink R $J$. Effectiveness of CPAP in the treatment of bronchomalacia in infants. A bronchoscopic evaluation. Crit Care Med 1986; 14:(2) 125-127.

14. Evans W A. Congenital obstructions of respiratory tract and thoracic malformation. Am J Roentgen
1949; 62: 167.

15. WITTENBoRG $M$ H, Gyepes M T, CROCKER D. Tracheal Dynamics in infants with respiratory dis- $\frac{\widehat{D}}{\mathrm{D}}$ tress stridor and collapsing trachea. Radiology 1967; 86: 653.

16. Berlinger N T, Lucas R A, Foker J. Pulmonaryo Arteriopexy to relieve tracheobronchial compression by dilated pulmonary arteries. Ann Otol $\overrightarrow{\vec{c}}$ Rhinol Laryngol 1984; 93: 473-476.

17. Mair E A, Parsons D S, Lally K P. Treatment of bronchomalacia with expanding endobronchialo stents. Arch Otolaryngol Head Neck Surg 1990; 116: $1087-1090$

18. Smith K P, Cavett C $M$. Segmental bron-o chomalacia - successful surgical correction in an ${ }^{\text {s }}$ infant. J Pediatr Surg 1985; 20: 240-241. 